\title{
The long-term prognostic impact of sentinel lymph node biopsy in patients with primary cutaneous melanoma: a prospective study with 10-year follow-up
}

\author{
Mattia Portinari', Gabriele Baldini' ${ }^{2}$, Massimo Guidoboni ${ }^{3}$, Alessandro Borghi ${ }^{4}$, Stefano Panareo ${ }^{5}$, \\ Simona Bonazza', Gianlorenzo Dionigi', Paolo Carcoforo' ${ }^{1}$
}

\author{
${ }^{1}$ Department of Surgery and Department of Morphology, Surgery and Experimental Medicine, S. Anna University Hospital and \\ University of Ferrara, Ferrara, Italy \\ ${ }^{2}$ Department of Anesthesia, McGill University Health Centre, Montreal General Hospital, Montreal, Canada \\ 3Immunotherapy and Somatic Cell Therapy Unit, Istituto Scientifico Romagnolo per lo Studio e la Cura dei Tumori (IRST) IRCCS, \\ Meldola (FC), Italy \\ ${ }^{4}$ Department of Medical Sciences, Section of Dermatology, S. Anna University Hospital and University of Ferrara, Ferrara, Italy \\ ${ }^{5}$ Unit of Nuclear Medicine, Department of Diagnostic Imaging, S. Anna University Hospital, Ferrara, Italy \\ ${ }^{6}$ Division for Endocrine and Minimally Invasive Surgery, Department of Human Pathology in Adulthood and Childhood "G. Barresi", \\ University Hospital "G. Martino", University of Messina, Messina, Italy
}

\begin{abstract}
Purpose: Sentinel lymph node (SLN) biopsy (SLNB) is widely accepted for staging of melanoma patients. It has been shown that clinico-pathological features such as Breslow thickness, ulceration, age, and sex are better predictors of relapse and survival than SLN status alone. The aims of this study were to evaluate the long-term (10-year) prognostic impact of SLNB and to determine predictive factors associated with SLN metastasis, relapse, and melanoma specific mortality (MSM). Methods: This was a prospective observational study on 289 consecutive patients with primary cutaneous melanoma who underwent SLNB from January 2000 to December 2007, and followed until January 2014, at an Italian academic hospital. Results: SLN was positive in 64 patients (22.1\%). The median follow-up was 116 months (79-147 months). Tenyear disease-free survival and melanoma specific survival were poor in patients with positive SLN $158.7 \%$ and $66.4 \%$, respectively). Only the increasing Breslow thickness resulted independently associated to an increased risk of SLN metastasis. Cox regression analysis showed that a Breslow thickness $>2 \mathrm{~mm}$ was an independent predictor of relapse, and male sex and Breslow thickness $>2 \mathrm{~mm}$ was a predictor of MSM. At 10 years, SLN metastasis was not significantly associated to either relapse or MSM.

Conclusion: After the fifth year of follow-up, SLN metastasis is not an independent predictive factor of relapse or mortality which are mainly influenced by the characteristics of the primary tumor and of the patient. Patients with a Breslow thickness $>2 \mathrm{~mm}$ regardless of the SLN status should be considered at high risk for 10-year relapse and mortality.

[Ann Surg Treat Res 2018;95(5):286-296]
\end{abstract}

Key Words: Melanoma, Sentinel lymph node biopsy, Prospective studies, Survival analysis, Risk factors

Received February 5, 2018, Revised April 8, 2018, Accepted June 1, 2018

Corresponding Author: Mattia Portinari

Department of Surgery and Department of Morphology, Surgery, and Experimental Medicine, S. Anna University Hospital and University of Ferrara, Via Aldo Moro, 8 Stanza 23439 (1C2), 44124 Ferrara (Cona), Italy

Tel: +39-0532-236100, Fax: +39-0532236100

E-mail: mattia.portinari@unife.it

ORCID code: https://orcid.org/0000-0003-0528-3786
Copyright (c) 2018, the Korean Surgical Society

(c) Annals of Surgical Treatment and Research is an Open Access Journal. All articles are distributed under the terms of the Creative Commons Attribution NonCommercial License (http://creativecommons.org/licenses/by-nc/4.0/) which permits unrestricted non-commercial use, distribution, and reproduction in any medium, provided the original work is properly cited. 


\section{INTRODUCTION}

Wide local excision (WLE) and sentinel lymph node biopsy (SLNB) are widely accepted as the standard of care for correct lymphatic basin staging for patients with clinically localized malignant melanoma [1]. The utility of SLNB has been correlated with depth of invasion of the primary tumor, and is a routine management in patients with melanoma thicker than $1 \mathrm{~mm}$ and may be considered for thin lesions with high-risk characteristics (e.g., ulceration, lymphovascular invasion, high mitotic rate) [2,3]. However, doubts have been cast regarding the efficacy of SLNB in predicting long-term survival and disease progression [4]. It has been shown that SLN status is an important predictor of relapse-free survival and overall survival; however, a combination of clinico-pathological features in a mathematic model (i.e., thickness, mitotic rate, ulceration, vessel invasion, site, age, and sex) gave a better prediction of relapse and survival than sentinel lymph node (SLN) status alone. Combining this model with the SLN status produced a small increase in the predictive value of these outcome parameters [5].

Having shown both the staging accuracy and pathological specificity of the SLNB technique, Morton et al. [6] postulated that this minimally invasive alternative to radical regional lymphadenectomy could not only reliably identify patients with clinically occult nodal metastases, but would also favorably affect the oncological outcomes. On that basis, they designed a randomized controlled trial (the International Multicenter Selective Lymphadenectomy Trial - MSLT-I), in patients with clinically localized primary cutaneous melanoma, to determine the long-term survival impact of SLNB followed by immediate radical lymphadenectomy (for SLN metastases) compared to observation and delayed lymphadenectomy when nodal metastases become clinically apparent . However, MSLT-I failed to demonstrate a significant treatment-related difference in the 10-year melanoma specific survival (MSS) rate in the overall study population [6-8].

The aims of this study were to evaluate, in patients with clinically localized, node-negative, primary cutaneous melanoma who underwent WLE/SLNB: (1) the long-term (10year) prognostic impact of SLNB on disease-free survival (DFS) and MSS; (2) the predictive factors associated with SLN metastasis, relapse, and melanoma specific mortality (MSM).

\section{METHODS}

This was a prospective observational, single institution study on 289 consecutive patients with primary cutaneous melanoma who underwent WLE and SLNB from January 2000 to December 2007, followed until January 2014, at the S. Anna University Hospital of Ferrara (Italy). This clinical trial initially
(2000-2002) was part of a prospective multicenter Italian observational study (SOLISM-IMI) [9,10] of lymphatic mapping and SLNB in clinically localized melanoma with the aim of studying both the influence of some technical aspects of the SLN mapping and biopsy, and the long-term prognostic impact of WLE/SLNB [9,10]. After this period, and following local ethics board approval and patients' consent, the enrollment was continued at our institution until 2007 (Institutional Review Board number: 12/99; update 01/03). There were no significant changes made to the clinical protocol methodology once the trial was initiated.

All consecutive patients with a Breslow lesion $>1 \mathrm{~mm}$ or $<1$ $\mathrm{mm}$ with ulceration and/or Clark level IV-V were considered for lymphatic mapping and SLNB. During the enrollment phase of the study (2000-2007), immediate radical regional lymphadenectomy was performed for nodal metastatic tumor deposit $>0.2 \mathrm{~mm}$ in diameter identified on pathological evaluation of the SLN(s), while it was not performed in patients with tumor deposits $\leq 0.2 \mathrm{~mm}$ and in patients who refused the procedure. Patients with clinical metastasis detected preoperatively by palpation or ultrasound examination were excluded.

The SLN mapping technique, the operative procedure, and the pathological analysis methods have been described in detail previously [10].

\section{Adjuvant therapy}

Patients with lymph node metastases were sent to adjuvant therapy with IFN- $\alpha$ according to the Kirkwood regimen [11]; patients with negative SLN were only tracked over time to identify any recurrences.

\section{False negative cases}

Patients with negative SLN who developed regional lymph node metastases during the follow-up period without preceding local relapse or in-transit metastases were considered false negative cases. The false negative rate (FNR) for SLNB was calculated as the false negative cases over the sum of the true positive (i.e., patients with positive SLN) plus the false negative cases, multiplied by 100 . Patients who developed distant metastasis or in-transit metastasis during the follow-up period were not considered false-negatives.

\section{Statistical analysis}

According to the American Joint Committee on Cancer (AJCC) 7th edition [12,13], for statistical analysis, SLN has been considered positive in the presence of nodal tumor deposits of any size, and patients were divided into 2 groups according to the SLN status.

The Shapiro-Wilk test was used to assess the assumption of normality and data were expressed as median (interquartile 
range, 25-75) according to the distribution. Categorical data are presented as absolute number and percentage (\%). Data were analyzed using the chi-square and Mann-Whitney tests as appropriate.

Actuarial survival data was calculated from the date of SLNB to either the time of known death or most recent follow-up. Patients lost to follow-up were censored. DFS was calculated as the length of time after SLNB during which no disease is found. Only deaths caused by cutaneous melanoma (defined as patients who died in the absence of any other medical complications) were considered in the survival analyses. MSS and DFS were estimated using the Kaplan-Meier product limit method. A log-rank test was run to determine if there were differences in the survival distribution for the different clinical variables.

Logistic regression analysis was employed to assess factors associated with SLN metastasis, while Cox regression analysis was performed to evaluate predictors of relapse and MSM. A Spearman Rank Order correlation was run to determine the relationship between Breslow thickness and Clark level. There was a strong, positive correlation between these variables, which was statistically significant ( $r s=0.698, \mathrm{P}<0.001$ ).
Thus, Clark level was excluded from the regression analyses. Significance was considered for values of $\mathrm{P}<0.05$. Statistical analysis was performed with IBM SPSS Statistics ver. 24.0 (IBM Co., Armonk, NY, USA).

\section{RESULTS}

\section{Baseline data and subjects analyzed}

The median number of excised SLNs was 1 (1-2). SLN was positive in 64 patients (22.1\%) and negative in 225 (77.9\%). Among patients with positive SLN, 59 patients (92.2\%) had lymph node metastatic tumor deposit $>0.2 \mathrm{~mm}$ and 11 of these refused the regional lymphadenectomy; and 5 patients (7.8\%) had nodal metastatic deposit $\leq 0.2 \mathrm{~mm}$ and the lymphadenectomy was not performed. The FNR for SLNB was $12.3 \%$ (9 of 73). Table 1 summarizes patient and tumor characteristics according to SLN status and suggests that lymph node metastases were more common in patients with ages $>60$ years, Breslow thickness $>2 \mathrm{~mm}$, Clark level IV-V, and ulcerated melanoma. Table 2 shows that in patients older than 60 years ulcerated melanomas significantly prevail with a Breslow thickness of $>2 \mathrm{~mm}$, and are positive for SLN.

Table 1. Demographic data and baseline characteristics

\begin{tabular}{|c|c|c|c|}
\hline Variable & $\begin{array}{c}\text { Negative sentinel } \\
\text { lymph node }(n=225)\end{array}$ & $\begin{array}{c}\text { Positive sentinel } \\
\text { lymph node }(n=64)\end{array}$ & P-value \\
\hline Sex & & & 0.156 \\
\hline Male & $113(50.2)$ & 39 (60.9) & \\
\hline Female & $112(49.8)$ & $25(39.1)$ & \\
\hline Age (yr) & & & 0.032 \\
\hline$\leq 40$ & $42(18.7)$ & $13(20.3)$ & \\
\hline $41-60$ & $99(44.0)$ & $17(26.6)$ & \\
\hline$>60$ & $84(37.3)$ & $34(53.1)$ & \\
\hline Tumor site & & & 0.622 \\
\hline Arm & $46(20.4)$ & $12(18.8)$ & \\
\hline Leg & $73(32.4)$ & $26(40.6)$ & \\
\hline Trunk & $94(41.8)$ & $24(37.5)$ & \\
\hline Head or neck & $12(5.3)$ & $2(3.1)$ & \\
\hline Breslow thickness $(\mathrm{mm})^{\mathrm{a})}$ & & & $<0.001$ \\
\hline$\leq 1$ & $84(40.4)$ & $4(6.5)$ & \\
\hline$>1, \leq 2$ & $78(37.5)$ & $16(25.8)$ & \\
\hline$>2, \leq 4$ & $36(17.3)$ & $24(38.7)$ & \\
\hline$>4$ & $10(4.8)$ & $18(29.0)$ & \\
\hline Clark level $^{\text {b) }}$ & & & $<0.001$ \\
\hline II & $45(21.8)$ & $2(3.3)$ & \\
\hline III & $95(46.1)$ & $18(30.0)$ & \\
\hline IV & $62(30.1)$ & $34(56.7)$ & \\
\hline V & $4(1.9)$ & $6(10.0)$ & \\
\hline Ulceration $^{c)}$ & & & $<0.001$ \\
\hline Absent & $181(83.0)$ & $30(47.6)$ & \\
\hline Present & $37(17.0)$ & $33(52.4)$ & \\
\hline
\end{tabular}

Values are presented as number (\%).

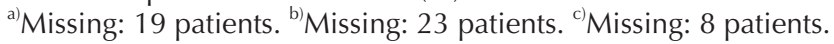


Table 2. Characteristics of patients grouped by age

\begin{tabular}{|c|c|c|c|c|c|c|c|c|c|}
\hline & \multicolumn{2}{|c|}{ Breslow thickness (mm) } & \multirow[b]{2}{*}{ P-value } & \multicolumn{2}{|c|}{ Ulceration } & \multirow[b]{2}{*}{ P-value } & \multicolumn{2}{|c|}{ SLN status } & \multirow[b]{2}{*}{ P-value } \\
\hline & $\begin{array}{c}\leq 2 \\
(\mathrm{n}=182)\end{array}$ & $\begin{array}{c}>2 \\
(\mathrm{n}=88)\end{array}$ & & $\begin{array}{l}\text { Absent } \\
(\mathrm{n}=211)\end{array}$ & $\begin{array}{l}\text { Present } \\
(\mathrm{n}=70)\end{array}$ & & $\begin{array}{l}\text { Negative } \\
(\mathrm{n}=225)\end{array}$ & $\begin{array}{l}\text { Positive } \\
(\mathrm{n}=64)\end{array}$ & \\
\hline Age (yr) & & & $<0.001$ & & & $<0.001$ & & & 0.030 \\
\hline$\leq 60(\mathrm{n}=171)$ & $67.6 \%$ & $44.3 \%$ & & $66.8 \%$ & $37.1 \%$ & & $62.7 \%$ & $46.9 \%$ & \\
\hline$>60(\mathrm{n}=118)$ & $32.4 \%$ & $55.7 \%$ & & $33.2 \%$ & $62.9 \%$ & & $37.3 \%$ & $53.1 \%$ & \\
\hline
\end{tabular}

SLN, sentinel lymph node.

Table 3. Five- and 10-year disease free survival (DFS) and melanoma specific survival (MSS) according to patients and melanoma characteristics, and AJCC stratification

\begin{tabular}{|c|c|c|c|c|c|c|c|}
\hline \multirow{2}{*}{ Variable } & \multirow{2}{*}{ Total } & \multicolumn{3}{|c|}{ DFS } & \multicolumn{3}{|c|}{ MSS } \\
\hline & & 5 -Year (\%) & $10-Y e a r(\%)$ & P-value & 5 -Year (\%) & 10-Year (\%) & P-value \\
\hline Sex & & & & 0.040 & & & 0.012 \\
\hline Male & 152 & 78.5 & 75.5 & & 84.4 & 81.0 & \\
\hline Female & 137 & 90.5 & 84.1 & & 94.8 & 91.4 & \\
\hline Age (yr) & & & & 0.002 & & & 0.003 \\
\hline$\leq 40$ & 55 & 90.7 & 84.6 & & 90.8 & 90.8 & \\
\hline $41-60$ & 116 & 88.7 & 87.8 & & 93.9 & 92.8 & \\
\hline$>60$ & 118 & 76.8 & 69.2 & & 84.3 & 76.8 & \\
\hline Tumor site & & & & 0.255 & & & 0.800 \\
\hline Arm & 58 & 86.0 & 84.0 & & 94.7 & 91.2 & \\
\hline Leg & 99 & 82.5 & 72.0 & & 89.7 & 82.7 & \\
\hline Trunk & 118 & 85.6 & 84.4 & & 87.2 & 86.3 & \\
\hline Head or neck & 14 & 77.9 & 77.9 & & 83.3 & 83.3 & \\
\hline Breslow thickness $(\mathrm{mm})^{\mathrm{a})}$ & & & & $<0.001$ & & & $<0.001$ \\
\hline$\leq 1$ & 88 & 96.6 & 96.6 & & 98.9 & 97.7 & \\
\hline$>1, \leq 2$ & 94 & 91.4 & 83.6 & & 93.5 & 90.7 & \\
\hline$>2, \leq 4$ & 60 & 72.9 & 62.8 & & 82.9 & 75.5 & \\
\hline$>4$ & 28 & 49.9 & 49.9 & & 58.6 & 50.5 & \\
\hline Clark level $^{\text {b) }}$ & & & & $<0.001$ & & & $<0.001$ \\
\hline II & 47 & 100.0 & 100.0 & & 100.0 & 100.0 & \\
\hline III & 113 & 86.7 & 85.3 & & 91.2 & 90.2 & \\
\hline IV & 96 & 80.8 & 68.0 & & 86.0 & 78.1 & \\
\hline V & 10 & 38.9 & 38.9 & & 55.6 & 44.4 & \\
\hline Ulceration $^{c}$ & & & & $<0.001$ & & & $<0.001$ \\
\hline Absent & 211 & 90.4 & 86.8 & & 93.2 & 90.4 & \\
\hline Present & 70 & 66.1 & 56.8 & & 78.0 & 71.9 & \\
\hline Sentinel lymph node status & & & & $<0.001$ & & & $<0.001$ \\
\hline Negative & 225 & 90.1 & 85.4 & & 95.0 & 91.4 & \\
\hline Positive & 64 & 62.9 & 58.7 & & 69.7 & 66.4 & \\
\hline AJCC stage ${ }^{\mathrm{d})}$ & & & & $<0.001$ & & & $<0.001$ \\
\hline $\mathrm{IA}$ & 83 & 97.6 & 97.6 & & 98.8 & 95.7 & \\
\hline IB & 65 & 95.3 & 89.6 & & 95.2 & 92.9 & \\
\hline IIA & 36 & 88.9 & 71.5 & & 91.7 & 79.9 & \\
\hline IIB & 17 & 58.2 & 58.2 & & 82.4 & 82.4 & \\
\hline IIC & 7 & 53.6 & 53.6 & & 85.7 & 42.9 & \\
\hline III & 64 & 62.9 & 58.7 & & 69.7 & 66.4 & \\
\hline
\end{tabular}

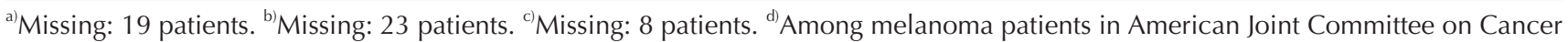
(AJCC) stage I and II, in 17 patients the Breslow thickness and/or the ulceration were not available, thus these patients were not stratified and then they were not included in the survival analysis according to AJCC staging. 
Long-term (10 years) prognostic impact of SLNB: outcomes analysis, DFS, and MSS

The median follow-up was 116 months (79-147 months). Thirty out of 225 patients (13.3\%) with negative SLN had relapse during the follow-up period, and 19 of these (63.3\%) died. Otherwise, 26 out of 64 patients (40.6\%) with positive SLN had relapse during the follow-up period, and 21 of these (80.8\%) died. Most of the deaths that occurred during the follow-up period were observed within the first 5 years $(75.0 \%$; 30 of 40 ), while the remaining deaths occurred over the next five years (25.0\%; 10 of 40 ). Eight out of 10 patients who died after the fifth year of follow-up were SLN negative at the time of
A

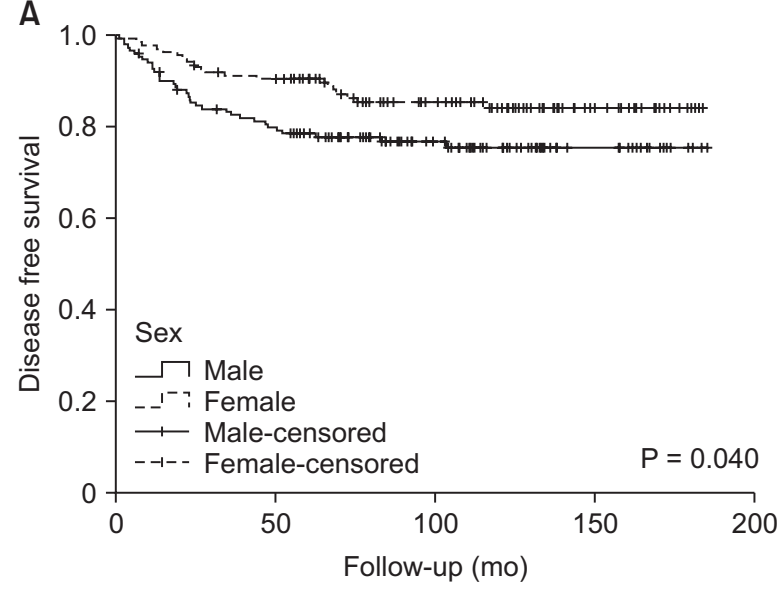

C

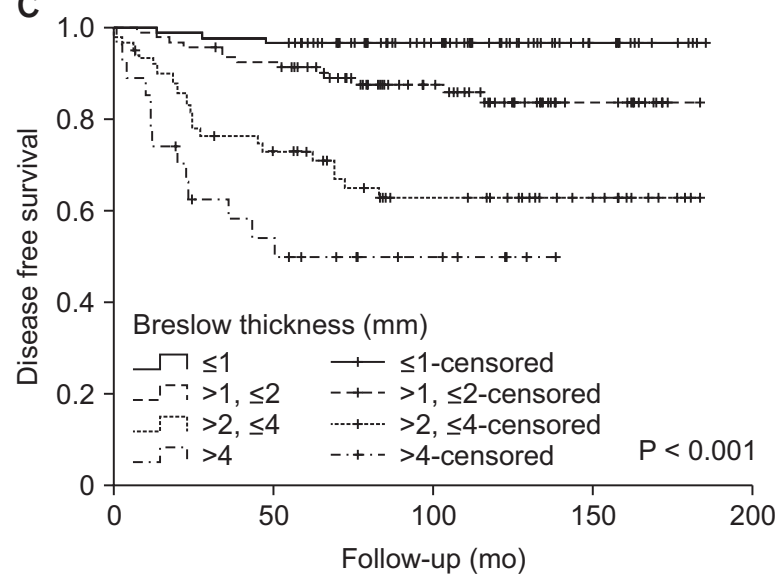

E

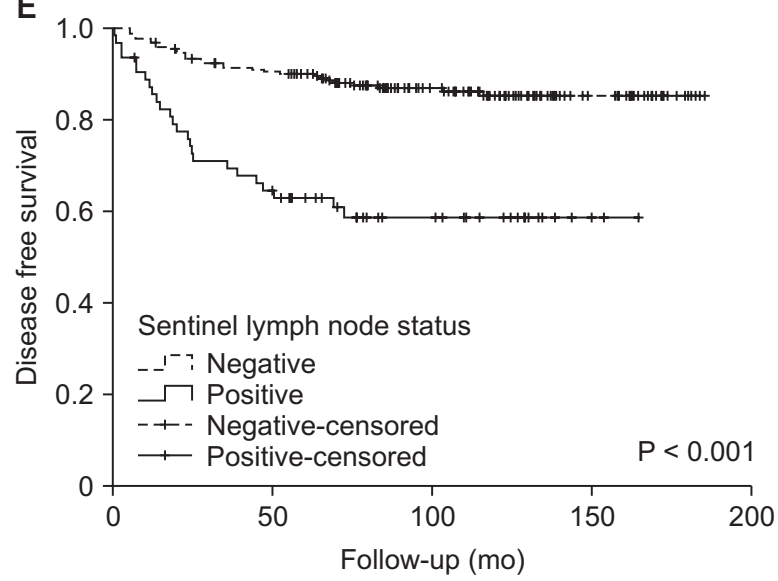

B

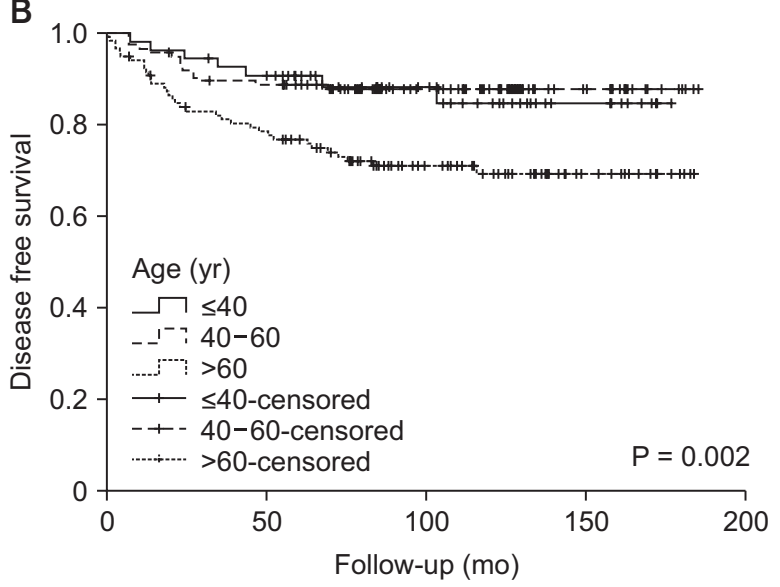

D

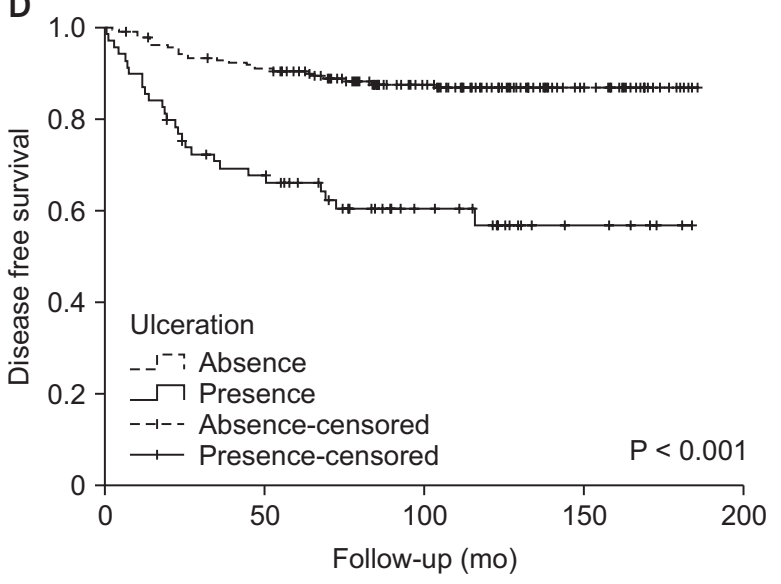

F

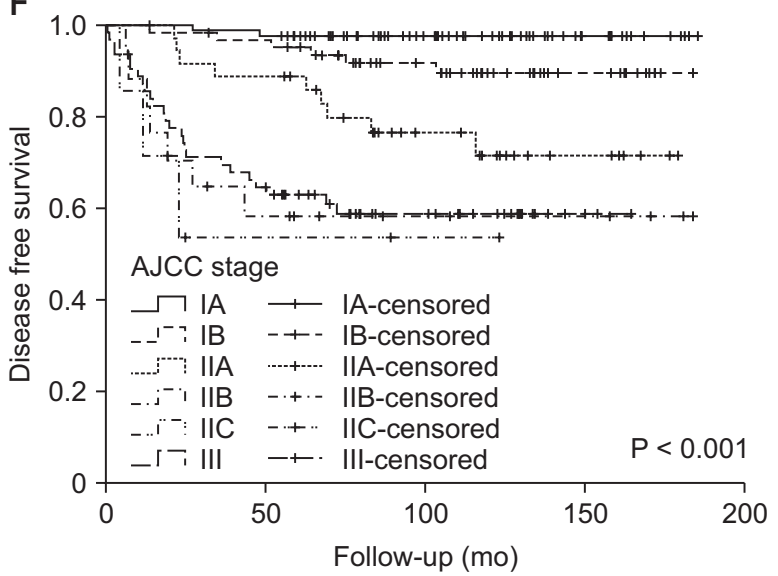

Fig. 1. Disease free survival. The panels show the disease free survival of melanoma patients according to sex (A), age (B), Breslow thickness (C), ulceration (D), sentinel lymph node status (E), and American Joint Committee on Cancer (AJCC) stratification (F). 

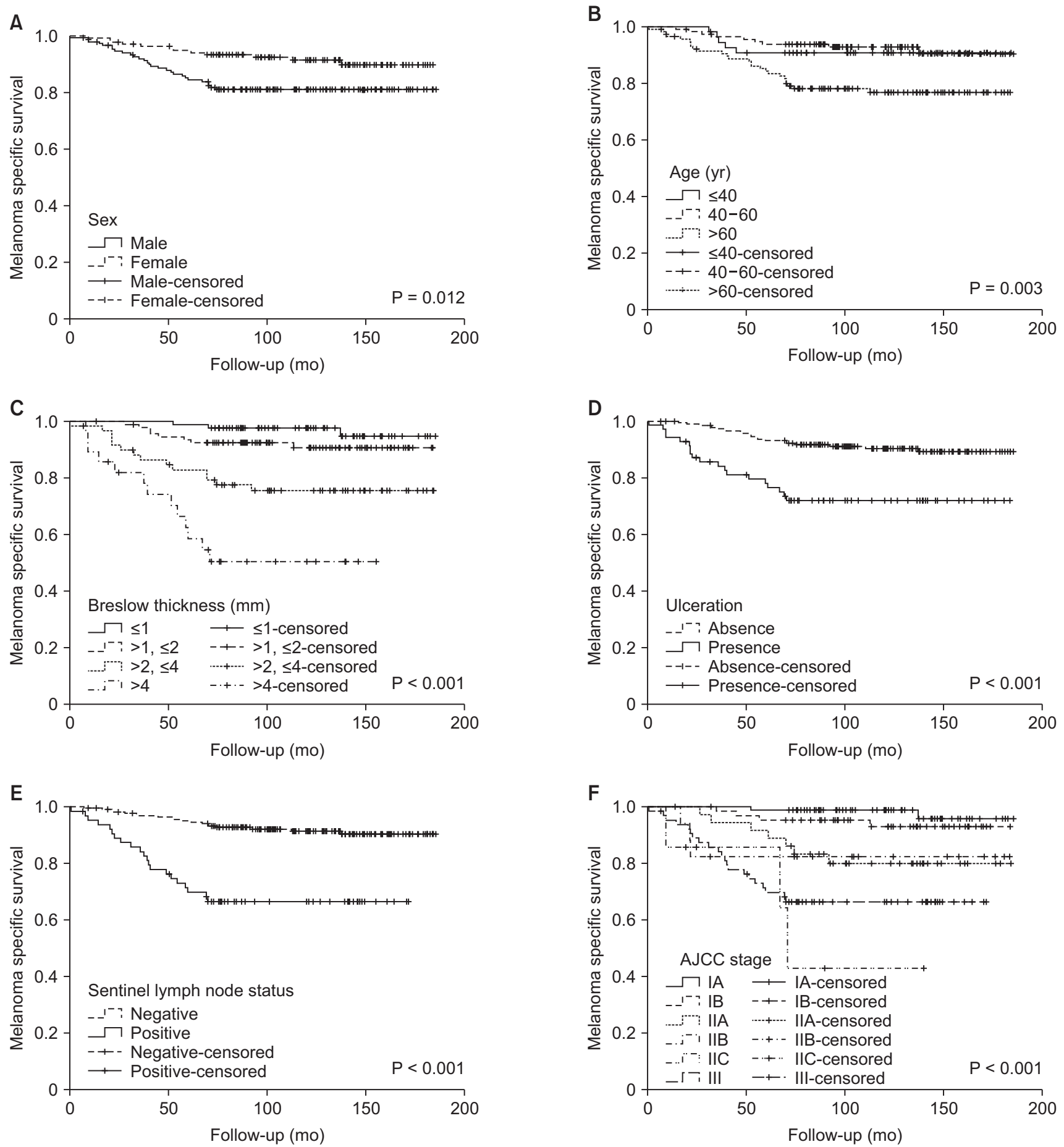

Fig. 2. Melanoma specific survival. The panels show the melanoma specific survival of melanoma patients according to sex (A), age (B), Breslow thickness (C), ulceration (D), sentinel lymph node status (E), and American Joint Committee on Cancer (AJCC) stratification $(\mathrm{F})$.

pathological examination. In most of patients with negative SLN, recurrences were observed within the first 5 years (22 of 30; 73.3\%), while the remaining patients experienced relapse over the next 4 years ( 8 of $30 ; 26.7 \%$ ). The patterns of recurrence in the negative SLN group vs. positive SLN group were: local recurrence ( 3 patients vs. 7 patients), in-transit metastasis (9 patients vs. 7 patients), regional lymph node metastasis (9 patients vs. 9 patients); lymph node metastasis in other site compared to SLN basin (5 patients vs. 2 patients); liver metastasis ( 4 patients vs. 9 patients); lung metastasis ( 9 patients 
Table 4. Association between baseline characteristics and sentinel lymph node metastasis according to logistic regression analysis adjusted for potential confounders (sex, age, tumor site, Breslow thickness, and ulceration)

\begin{tabular}{|c|c|c|c|c|}
\hline \multirow{3}{*}{ Variable } & \multicolumn{4}{|c|}{ Sentinel lymph node metastasis } \\
\hline & \multicolumn{2}{|c|}{ Unadjusted model } & \multicolumn{2}{|c|}{ Full adjusted model } \\
\hline & OR $(95 \% \mathrm{Cl})$ & P-value & OR $(95 \% \mathrm{Cl})$ & P-value \\
\hline \multicolumn{5}{|l|}{ Sex (ref: female) } \\
\hline Male & $1.55(0.88-2.72)$ & 0.131 & $1.46(0.71-3.02)$ & 0.305 \\
\hline \multicolumn{5}{|l|}{ Age (ref: $\leq 40 \mathrm{yr}$ ) } \\
\hline $41-60$ & $0.56(0.25-1.24)$ & 0.153 & $0.54(0.21-1.40)$ & 0.202 \\
\hline$>60$ & $1.31(0.63-2.74)$ & 0.477 & $0.81(0.33-1.99)$ & 0.640 \\
\hline \multicolumn{5}{|l|}{ Tumor site (ref: Arm) } \\
\hline Leg & $1.37(0.63-2.97)$ & 0.432 & $1.70(0.65-4.42)$ & 0.278 \\
\hline Trunk & $0.98(0.45-2.13)$ & 0.957 & $1.17(0.47-2.90)$ & 0.740 \\
\hline Head or neck & $0.64(0.13-3.25)$ & 0.589 & $0.74(0.12-4.65)$ & 0.748 \\
\hline \multicolumn{5}{|c|}{ Breslow thickness (ref: $\leq 1 \mathrm{~mm}$ ) } \\
\hline$>1, \leq 2$ & $4.31(1.38-13.45)$ & 0.012 & $3.43(1.07-11.07)$ & 0.039 \\
\hline$>2, \leq 4$ & $14.00(4.53-43.26)$ & $<0.001$ & $9.32(2.80-30.99)$ & $<0.001$ \\
\hline$>4$ & $37.80(10.65-134.11)$ & $<0.001$ & $21.45(5.41-85.43)$ & $<0.001$ \\
\hline \multicolumn{5}{|l|}{ Ulceration (ref: absence) } \\
\hline Presence & $5.38(2.93-9.88)$ & $<0.001$ & $1.98(0.95-4.13)$ & 0.070 \\
\hline
\end{tabular}

$\mathrm{OR}$, odds ratio; $\mathrm{Cl}$, confidence interval.

vs. 13 patients); brain metastasis (5 patients vs. 4 patients); bone metastasis ( 3 patients vs. 3 patients); spleen metastasis (1 patient vs. 1 patient); eye metastasis (1 patient vs. 0 patient); metastasis of the gingiva (1 patient vs. 0 patient); gastric metastasis ( 1 patient vs. 0 patient); metastasis of the pancreas ( 1 patient vs. 0 patient); metastasis of the omentum (0 patient vs. 1 patient); peritoneal metastasis ( 0 patient vs. 1 patient); metastasis of the kidney ( 0 patient vs. 3 patients); bowel metastasis ( 0 patient vs. 1 patient).

In all study population, at 5 and 10 years: (1) the rate of death from melanoma was $12.0 \%$ (30 of 251) and 28.4\% (40 of 141), respectively; (2) DFS was $84.2 \%$ and $79.6 \%$, respectively; and (3) MSS was $89.4 \%$ and $85.9 \%$, respectively.

At 10 years, the DFS and MSS were significantly lower in male patients and in those with ages $>60$ years, ulcerated melanoma, and SLN metastases (Table 3; Figs. 1, 2). Furthermore, an increase in both Breslow thickness and Clark level determines a significant decrease in DFS and MSS.

DFS and MSS were statistically different among patients in AJCC stage I, II, and III ( $<$ 0.001) (Table 3; Figs. 1, 2). However, there were no statistically significant differences among patients with stage IIB, IIC, and III with regard to 10-year DFS $(58.2 \%$ vs. $53.6 \%$ vs. $58.7 \%$, respectively; $\mathrm{P}=0.826)$ and among patients in stage IIC and III concerning 10 -year MSS ( $42.9 \%$ vs. $66.4 \%$, respectively; $P=0.406$ ) (Figs. 1,2 ).

Of note, in the false negative patients, 5- and 10-year MSS were $66.7 \%$ and $22.2 \%$, respectively. In these patients, the regional lymph node metastases appeared during the first 4 years of follow-up.

\section{Predictive factors associated with SLN metastasis, relapse, and MSM}

Full-adjusted logistic regression analysis showed that only the increasing Breslow thickness of the primary lesion resulted independently associated with SLN metastases (Table 4).

Full-adjusted Cox regression analysis showed that: (1) only Breslow thickness $>2 \mathrm{~mm}$ was significantly associated to relapse; (2) male sex and Breslow thickness $>2 \mathrm{~mm}$ were significantly associated to MSM; (3) SLN metastasis was not significantly associated either to relapse or to MSM (Table 5).

\section{Subgroup survival analysis among patients with positive SLN}

A subgroup survival analysis comparing patients who underwent radical regional lymphadenectomy after SLNB $(n=$ 48) and patients in which the procedure was not performed ( $\mathrm{n}$ $=16$ ), shows that there were no significant differences in terms of 10 -year DFS (55.7\% vs. $68.8 \%$, respectively; $\mathrm{P}=0.430)$ and 10 year MSS ( $65.7 \%$ vs. $68.8 \%$, respectively; $\mathrm{P}=0.881$ ) between the 2 subgroups (Fig. 3).

\section{DISCUSSION}

This prospective observational study on melanoma patients 


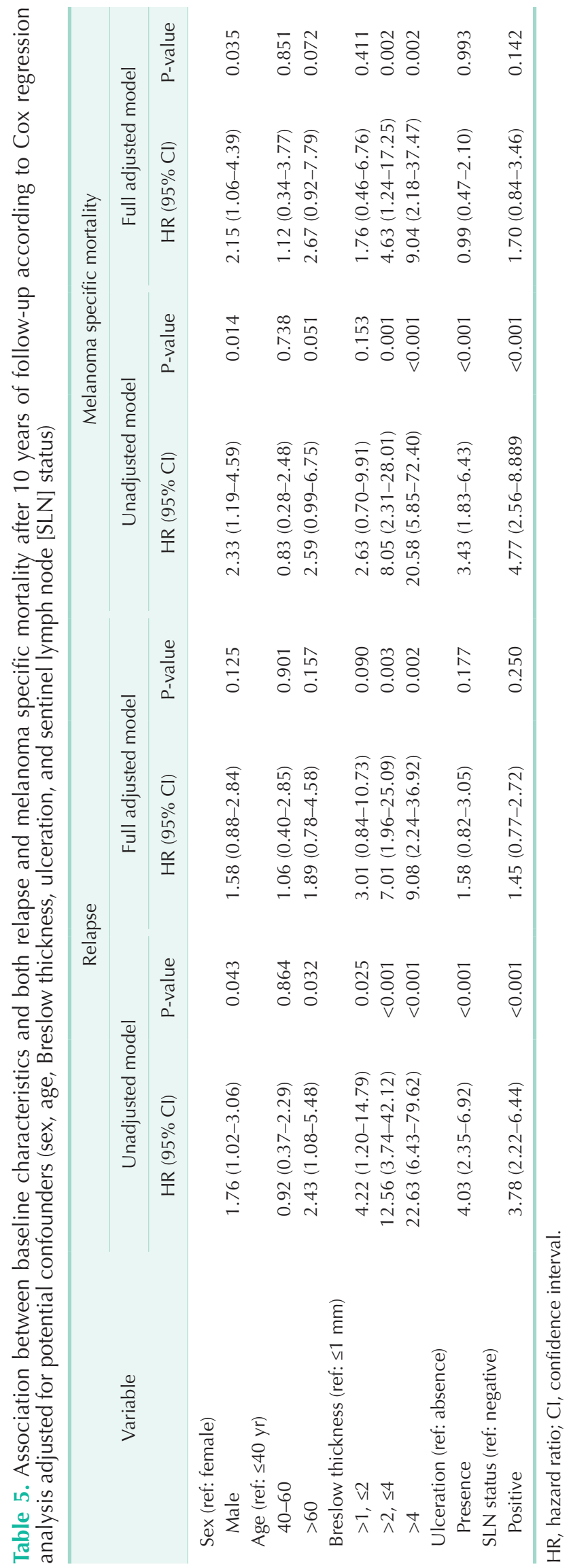

who underwent WLE/SLNB shows that: (1) 10-year DFS and MSS were significantly lower in patients with SLN metastasis; however, SLN positivity by itself does not predict recurrence or mortality after 5 years; (2) only the increasing Breslow thickness resulted independently associated to an increased risk of SLN metastases; (3) only Breslow thickness $>2 \mathrm{~mm}$ was an independent predictive factor of both 10-year relapse and mortality.

\section{Long-term (10 years) prognostic impact of SLNB: outcomes analysis, DFS, and MSS}

As reported by de Vries et al. [14], in our study the 10-year DFS and MSS were significantly lower in patients with SLN metastases, and the analysis of the entire study population showed an expected decline in 5-year survival over the followup period as most of the deaths were observed within the first 5 years, while the remaining deaths occurred over the following 5 years. However, $80 \%$ of patients who died after the fifth year of follow-up were SLN negative at the time of pathological examination. This suggests a slower progression of disease in some patients, supported by initial negative SLN, and a possible impact on long-term DFS and MSS of other factors rather than the SLN status. Jones et al. [15] showed that older age, increasing Breslow thickness, ulceration, and lesion located in the head and neck region are independent predictive factors of recurrence during the follow-up period in melanoma patients with negative SLN. Jones et al. [15] demonstrated that among patients with negative SLN, who experienced a recurrence, had a significantly decreased 5-year overall survival compared to patients who did not experience recurrence (68\% vs. $98 \%$ ).

MSLT-I trial failed to demonstrate that there is a significant treatment-related difference in the 10-year MSS rate in patients who underwent SLNB followed by immediate radical lymphadenectomy (for SLN metastases) compared to observation and delayed lymphadenectomy when nodal metastases become clinically apparent [6-8]. Furthermore, the MSLT-II trial in which patients with SLN metastasis were randomly assigned to nodal observation with ultrasound or immediate completion lymph node dissection showed that the latter procedure decreased the 3 years DFS but not the MSS [16]. Inspired by this conclusion, we performed a subgroup survival analysis among patients with positive SLN to evaluate the impact of radical regional lymphadenectomy on DFS and MSS, and no significant differences in these 2 oncological outcomes were found (Fig. 3). Also, the little but not significant survival benefit in favor of patients in which lymph node dissection was not performed may be influenced by the 5 patients with SLN metastasis $\leq 0.2 \mathrm{~mm}$ in this subgroup. On the other hand, these latter patients were not sent to adjuvant therapy with IFN because during the enrollment phase of the study regional nodal metastatic tumor deposit $>0.2 \mathrm{~mm}$ in diameter was 
used as the threshold for defining nodal metastasis. This may have favored the other group in which adjuvant therapy was performed in all patients due to the presence of positive SLN (lymph node tumor deposits $>0.2 \mathrm{~mm}$ ), reducing differences in DFS and MSS between the 2 groups. Indeed, Kirkwood et al. [11] in their randomized controlled trial showed that IFN- $\alpha$ determine a significant benefit in DFS and overall survival. Therefore, in this study, the regional radical lymphadenectomy in patients with positive SLN seems to have no significant treatment-related effect on DFS and MSS; however, due to both the small number of patients and the study design, these results must be interpreted with caution.

\section{Predictive factors of SLN metastasis}

White et al. [17] confirmed the predictive significance of the well-established variables, such as Breslow thickness, ulceration, and younger age as predictors of a positive SLN, and these data are supported by Bartlett and Karakousis [18]. With regard to the association between patients' age and SLN status, Chao et al. [19] demonstrated that the incidence of SLN metastasis declined with increasing age. It has been hypothesized that increased immune-competency in younger patients helps to explain the trend toward greater SLN positivity prior to systemic metastasis in this age group [19]. Carlson [20] had also proposed that dermal lymphatic atrophy and altered antigen presentation systems in the elderly predispose this population to the hematologic spread of melanoma, instead of metastasis through the SLN/regional nodal pathway. By contrast, in older patients ( $>60$ years old) positive SLN was associated with a higher occurrence of thick, ulcerated melanomas; and the tendency for more aggressive disease in the elderly population has been hypothesized to be related to a lack of self-examination, and a tendency to mistake early melanoma for other age-related skin changes, such as seborrheic keratosis
[21,22]. Moreover, elderly patients tend to overlook early signs of melanoma, such as changes in color or shape, but more often recognize the ominous signs of advanced melanoma, such as ulceration and bleeding [23]. In contrast to Chao et al. [19] and Carlson [20], in our series the incidence of SLN metastasis rose with increasing age (Table 1), and this might be supported by the fact that in elderly patients ulcerated melanomas prevail with Breslow thickness $>2 \mathrm{~mm}$ (Table 2). However, full-adjusted logistic regression analysis shows that only the increasing Breslow thickness of the primary lesion was independently associated with SLN metastases (Table 4).

In this study, the FNR for SLNB (12.3\%) compares well with other reports in which the distribution of FNR ranged from $0 \%$ to $34 \%$ and the weighted summary estimate was $12.5 \%$ (95\% confidence interval, 11.0-14.2) [24], and this supports our results in term of reproducibility of the SLNB technique. Interestingly, our FNR is lower than the FNR of Morton et al. [6] (19.4\%) in the largest trial on melanoma patients.

\section{Predictive factors of relapse and MSM}

The poor prognosis associated with metastatic melanoma compared to early-stage disease underlies the importance of defining prognostic factors for disease progression and longterm survival. Some authors suggest that Breslow depth and Clark's level have the most influence on long-term survival $[10,25,26]$, and have been shown to be linked variables [27]. Other factors, including increasing age and male sex, were shown to significantly influence 5 -year survival, but not to the same extent as tumor thickness $[4,10,18,25,28,29]$. However, the presence of ulceration seems to be strongly associated with haematogenous dissemination of metastasis [27]. Furthermore, SLN status was found as another strong predictor for recurrence [26,30] and survival $[10,18,25]$. By contrast, Topar et al. [4] in a prospective study showed that the proportion of patients
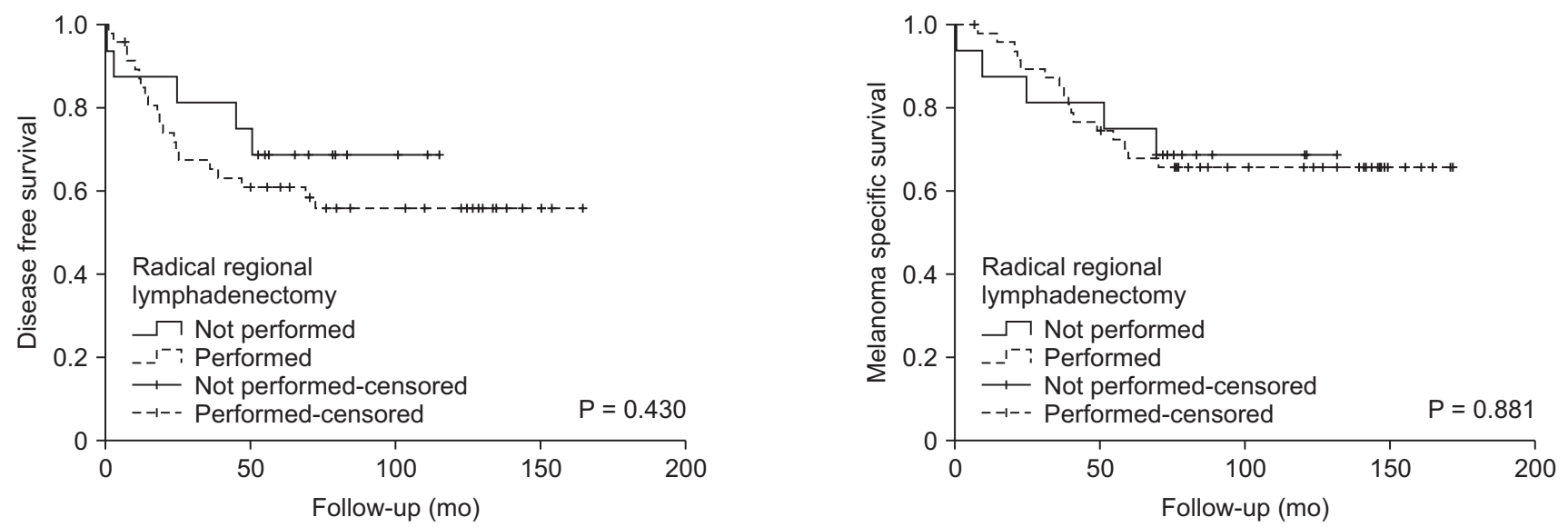

Fig. 3. Subgroup survival analysis. The panels show, among patients with positive sentinel lymph node, the survival analysis comparing patients who underwent radical regional lymphadenectomy after sentinel lymph node biopsy $(n=48)$ and patients in which the procedure was not performed $(\mathrm{n}=16)$. 
with both a progressive disease and a tumor-related death was not significantly higher in patients with positive SLN than in those with negative SLN. Therefore, they concluded that the SLN status is not a reliable prognostic factor for melanoma progression. Zogakis et al. [29], based on the hypothesis that the negative SLN in melanoma patients does not preclude recurrence of the disease, showed that the primary tumor thickness in this subgroup of patients was the most important prognostic factor for overall survival and DFS. Furthermore, it has been shown that clinico-pathological features in a mathematic model (i.e., thickness, mitotic rate, ulceration, vessel invasion, site, age, and sex) gave a better prediction of relapse and survival than SLN status alone [5]. In fact, in our study SLN metastasis was significantly associated neither to relapse nor to MSM, and after 5 years of follow-up the Breslow thickness affected these 2 long-term oncological outcomes more than the SLN metastasis, probably above all in patients with tumor negative SLN. However, it should be noted that most recurrences in both groups occurred within 5 years and $80 \%$ of patients who experienced recurrences after the first 5 years of follow-up were SLN negative. Thus, the distribution of recurrences in both groups and the late recurrences in patients with negative SLN may have influenced the 10-year predictive role of SLN status in the Cox regression analysis.

\section{Limitations of the study}

This study has some limitations which have to be pointed out. Firstly, the mitotic rate (available only in about $40 \%$ of patients enrolled in the study) has been considered another important predictor of survival after the beginning of our study, thus it was not included in the risk analysis. Secondly, this is not a controlled trial, thus the subgroup analysis on regional radical lymphadenectomy in patients with positive SLN in term of DFS and MSS must be interpreted with caution due to both the small number of patients and the study design.

In conclusion, this study confirmed the validity of SLNB for better tumor staging, and as a warning to identify which patients will experience a worse prognosis due to the positivity of SLN. However, after the fifth year of follow-up, SLN metastasis independently is not a predictive factor of relapse and mortality, and this circumstance might be affected by other factors that influence the positivity of SLN and increase the risk of 10-year relapse and MSM. Patients with a Breslow thickness $>2 \mathrm{~mm}$, regardless of the SLN status, should be considered high-risk patients for long-term relapse and mortality.

A prospective study with a larger sample of SLN negative patients with subsequent recurrence would be helpful to refine the analysis of risk factors in this group of patients.

\section{CONFLICTS OF INTEREST}

No potential conflict of interest relevant to this article was reported.

\section{REFERENCES}

1. Mozzillo N, Caracò C, Chiofalo MG, Celentano E, Lastoria S, Botti G, et al. Sentinel lymph node biopsy in patients with cutaneous melanoma: outcome after 3-year follow-up. Eur J Surg Oncol 2004:30:440-3.

2. Scoggins CR, Bowen AL, Martin RC 2nd, Edwards MJ, Reintgen DS, Ross MI, et al. Prognostic information from sentinel lymph node biopsy in patients with thick melanoma. Arch Surg 2010;145:622-7.

3. National Comprehensive Cancer Network. Melanoma (version 1.2018) [Internet]. Fort Wathington (PA): National Comprehensive Cancer Network; c2017 [cited 2017 Apr 12]. Available from: http://www.nccn. org/professionals/physician_gls/pdf/ melanoma.pdf.

4. Topar G, Eisendle K, Zelger B, Fritsch P.
Sentinel lymph node status in melanoma: a valuable prognostic factor? Br J Dermatol 2006;154:1080-7.

5. Mitra A, Conway C, Walker C, Cook M, Powell B, Lobo S, et al. Melanoma sentinel node biopsy and prediction models for relapse and overall survival. Br J Cancer 2010;103:1229-36.

6. Morton DL, Thompson JF, Cochran AJ, Mozzillo N, Nieweg OE, Roses DF, et al. Final trial report of sentinel-node biopsy versus nodal observation in melanoma. $\mathrm{N}$ Engl J Med 2014:370:599-609.

7. Sladden M, Zagarella S, Popescu C, Bigby M. No survival benefit for patients with melanoma undergoing sentinel lymph node biopsy: critical appraisal of the $\mathrm{Mu}$ lticenter Selective Lymphadenectomy
Trial-I final report. Br J Dermatol 2015;172: 566-71.

8. Kyrgidis A, Tzellos T, Mocellin S, Apalla Z, Lallas A, Pilati P, et al. Sentinel lymph node biopsy followed by lymph node dissection for localised primary cutaneous melanoma. Cochrane Database Syst Rev 2015;(5):CD010307.

9. Rossi CR, De Salvo GL, Trifiro G, Mocellin S, Landi G, Macripò G, et al. The impact of lymphoscintigraphy technique on the outcome of sentinel node biopsy in 1,313 patients with cutaneous melanoma: an Italian Multicentric Study (SOLISM-IMI). J Nucl Med 2006;47:234-41.

10. Testori A, De Salvo GL, Montesco MC, Trifiro G, Mocellin S, Landi G, et al. Clinical considerations on sentinel node 
biopsy in melanoma from an Italian multicentric study on 1,313 patients (SOLISM-IMI). Ann Surg Oncol 2009;16:201827.

11. Kirkwood JM, Strawderman MH, Ernstoff MS, Smith TJ, Borden EC, Blum RH. Interferon alfa-2b adjuvant therapy of high-risk resected cutaneous melanoma: the Eastern Cooperative Oncology Group Trial EST 1684. J Clin Oncol 1996:14:7-17.

12. Balch CM, Gershenwald JE, Soong SJ, Thompson JF, Atkins MB, Byrd DR, et al. Final version of 2009 AJCC melanoma staging and classification. J Clin Oncol 2009:27:6199-206.

13. Gershenwald JE, Soong SJ, Balch CM; American Joint Committee on Cancer (AJCC) Melanoma Staging Committee. 2010 TNM staging system for cutaneous melanoma....and beyond. Ann Surg Oncol 2010;17:1475-7.

14. de Vries M, Speijers MJ, Bastiaannet E, Plukker JT, Brouwers AH, van Ginkel RJ, et al. Long-term follow-up reveals that ulceration and sentinel lymph node status are the strongest predictors for survival in patients with primary cutaneous melanoma. Eur J Surg Oncol 2011;37:681-7.

15. Jones EL, Jones TS, Pearlman NW, Gao D, Stovall R, Gajdos C, et al. Longterm follow-up and survival of patients following a recurrence of melanoma after a negative sentinel lymph node biopsy result. JAMA Surg 2013;148:456-61.

16. Faries MB, Thompson JF, Cochran AJ, Andtbacka RH, Mozzillo N, Zager JS, et al. Completion dissection or observation for sentinel-node metastasis in melanoma. $\mathrm{N}$
Engl J Med 2017:376:2211-22.

17. White RL Jr, Ayers GD, Stell VH, Ding S, Gershenwald JE, Salo JC, et al. Factors predictive of the status of sentinel lymph nodes in melanoma patients from a large multicenter database. Ann Surg Oncol 2011;18:3593-600.

18. Bartlett EK, Karakousis GC. Current staging and prognostic factors in melanoma. Surg Oncol Clin N Am 2015;24:21527.

19. Chao C, Martin RC 2nd, Ross MI, Reintgen DS, Edwards MJ, Noyes RD, et al. Correlation between prognostic factors and increasing age in melanoma. Ann Surg Oncol 2004;11:259-64.

20. Carlson GW. Age and the incidence of sentinel lymph node metastases in melanoma. Ann Surg Oncol 2004;11:236-7.

21. Oliveria SA, Christos PJ, Halpern AC, Fine JA, Barnhill RL, Berwick M. Evaluation of factors associated with skin self-examination. Cancer Epidemiol Biomarkers Prev 1999;8:971-8.

22. Testori A, Stanganelli I, Della Grazia L, Mahadavan L. Diagnosis of melanoma in the elderly and surgical implications. Surg Oncol 2004;13:211-21.

23. Christos PJ, Oliveria SA, Berwick M, Guerry D4th, Elder DE, Synnestvedt M, et al. Signs and symptoms of melanoma in older populations. J Clin Epidemiol 2000; 53:1044-53.

24. Valsecchi ME, Silbermins D, de Rosa N, Wong SL, Lyman GH. Lymphatic mapping and sentinel lymph node biopsy in patients with melanoma: a meta-analysis. J Clin Oncol 2011;29:1479-87.
25. van Akkooi AC, de Wilt JH, Verhoef C, Graveland WJ, van Geel AN, Kliffen M, et al. High positive sentinel node identification rate by EORTC melanoma group protocol. Prognostic indicators of metastatic patterns after sentinel node biopsy in melanoma. Eur J Cancer 2006; 42:37280.

26. Balch CM, Soong SJ, Gershenwald JE, Thompson JF, Reintgen DS, Cascinelli $\mathrm{N}$, et al. Prognostic factors analysis of 17,600 melanoma patients: validation of the American Joint Committee on Cancer melanoma staging system. J Clin Oncol 2001;19:3622-34.

27. Balch CM, Sober AJ, Soong SJ, Gershenwald JE; AJCC Melanoma Staging Committee. The new melanoma staging system. Semin Cutan Med Surg 2003;22:42-54.

28. Murali R, Desilva C, Thompson JF, Scolyer RA. Factors predicting recurrence and survival in sentinel lymph node-positive melanoma patients. Ann Surg 2011;253: 1155-64.

29. Zogakis TG, Essner R, Wang HJ, Foshag LJ, Morton DL. Natural history of melanoma in 773 patients with tumor-negative sentinel lymph nodes. Ann Surg Oncol 2007; 14:1604-11.

30. Gershenwald JE, Thompson W, Mansfield $\mathrm{PF}$, Lee JE, Colome MI, Tseng $\mathrm{CH}$, et al. Multi-institutional melanoma lymphatic mapping experience: the prognostic value of sentinel lymph node status in 612 stage I or II melanoma patients. J Clin Oncol 1999;17:976-83. 